\title{
Volunteer effect and compromised randomization in the Mayo Project of screening for lung cancer
}

\author{
Lorenzo Dominioni • Albino Poli • \\ William Mantovani • Nicola Rotolo • \\ Andrea Imperatori
}

Received: 5 August 2010/Accepted: 12 October 2010/Published online: 23 October 2010

(C) The Author(s) 2010. This article is published with open access at Springerlink.com

\begin{abstract}
It has been confirmed recently that the volunteer effect in lung cancer screening is characterized by higher lung cancer mortality risk in self-selected screening participants. The Mayo Lung Project, the most influential trial of screening for lung cancer ever completed, was conducted in nonvolunteer Mayo Clinic outpatients, with a peculiar study design that rendered the randomization vulnerable to the volunteer effect. Of all nonvolunteers randomized in the Mayo Lung Project, only those allocated in the screened group were asked consent to participate in the trial. The final Mayo Lung Project report stated that 655 randomized nonvolunteers refused screening and were excluded from the study, thus documenting violation of the rule that no selection should occur after randomization. The long-term follow-up of the Mayo Lung Project showed an enigmatic result which has never been explained: the lung cancer mortality was $13 \%$ higher in the screening intervention group than in the control group [4.4 (95\% CI 3.9-4.9) vs. 3.9 (95\% CI 3.5-4.4) per 1,000 person-years; $P=0.09]$. Such overrepresented mortality is consistent with the volunteer effect and supports the concept that the Mayo Lung Project randomization was compromised by the post-randomization self-selection of participant nonvolunteers.
\end{abstract}

Keywords Compromised randomization - Lung cancer screening · Mayo lung project - Volunteer effect

L. Dominioni $(\bowtie) \cdot$ N. Rotolo $\cdot$ A. Imperatori Center for Thoracic Surgery, University of Insubria, Ospedale di Circolo, Viale Borri 57, 21100 Varese, Italy

e-mail: lorenzo.dominioni@uninsubria.it

A. Poli · W. Mantovani

Department of Public Health, University of Verona, Verona, Italy

\author{
Abbreviations \\ CXR Chest X-rays \\ CI Confidence interval \\ LC Lung cancer \\ MLP Mayo lung project
}

Dear Editor,

The volunteer effect has been studied extensively in screening trials for cancer of the breast, colon-rectum and prostate [1-3], but it has been scarcely investigated in the context of screening for lung cancer (LC). The Johns Hopkins Lung Project first documented that the LC mortality of volunteers screened by chest X-rays (CXR) was significantly higher than expected on the basis of two large population studies, namely the Veterans Study [observed/ expected LC mortality ratio $1.72 ; 95 \%$ confidence interval (CI) 1.28-2.18] and the American Cancer Society Study (observed/expected LC mortality ratio 1.46; 95\% CI 1.09-1.83) [4]. Recently, in a population-based study of smokers offered CXR screening we confirmed that the volunteer effect is characterized by significantly higher LC mortality risk in self-selected participants compared to nonparticipants (risk ratio 1.40; 95\% CI, 1.03-1.91) [5]. The volunteer effect may bias the results of comparative LC screening studies of nonvolunteers, if the latter are not randomized adequately. The Mayo Lung Project (MLP), the most influential trial of CXR screening for LC [6, 7], was conducted in nonvolunteer Mayo Clinic outpatients with a peculiar design that rendered the randomization vulnerable.

Indeed the details of the MLP randomization, described on page 1375 in the preliminary report [8], specify that: "the random assignment to the close-surveillance or the control group is made at the interview. Up to this point, 
the Mayo Lung Project has not been mentioned, and, if the assignment is to the control group, nothing is said of it and the interview ends. If the assignment is to the close-surveillance group, however, the interviewer explains that program to the candidate and obtains his informed consent and agreement to take part in it".

Accordingly, the MLP candidates were first randomized and subsequently only the nonvolunteers allocated in the screened group were asked consent to participate in the trial; because of that study design we hypothesize that the MLP randomization was likely compromised by the volunteer bias.

The final MLP report stated that 655 randomized nonvolunteers refused screening and were excluded from the study [9], thus documenting violation of the rule that no selection should occur after randomization. After such selection and exclusion of candidates, an important methodological weakness, there is no guarantee that the screening and control groups at baseline were well matched for all known and unknown LC risks [10]. Notably, the extended follow-up of the MLP showed two puzzling results: (1) in 16 years after the end of screening (1983-1999) the total number of newly diagnosed LCs was $11 \%$ greater in the screened group than in controls (379 vs. 340) [11], an excess certainly not attributable to screening overdiagnosis; (2) the LC mortality was $13 \%$ higher in the screening intervention group than in the control group [4.4 (95\% CI 3.9-4.9) vs. 3.9 (95\% CI 3.5-4.4) per 1,000 person-years; $P=0.09$ ] [12]. These enigmatic results are consistent with the volunteer effect in the LC screening group; moreover, they support the concept that the documented post-randomization selection of nonvolunteers compromised the MLP randomization.

Open Access This article is distributed under the terms of the Creative Commons Attribution Noncommercial License which permits any noncommercial use, distribution, and reproduction in any medium, provided the original author(s) and source are credited.

\section{References}

1. Richardson A, Wells JE. Breast cancer screening: the effect of self selection for screening on comparisons of randomized controlled trials. J Med Screen. 1997;4:16-8.

2. Blom J, Yin L, Lidén A, Dolk A, Jeppson B, Pahlman L, et al. A 9-year follow-up study of participants and nonparticipants in sigmoidoscopy screening: importance of self-selection. Cancer Epidemiol Biomarkers Prev. 2008;17:1163-8.

3. Otto SJ, Schroeder FH, De Koning HJ. Low all-cause mortality in the volunteer-based Rotterdam section of the European randomised study of screening for prostate cancer: self-selection bias? J Med Screen. 2004;11:89-92.

4. Levin ML, Tockman MS, Frost JK, Ball WC Jr. Lung cancer mortality in males screened by chest X-ray and cytologic sputum examination: a preliminary report. Recent Results Cancer Res. 1982;82:138-46.

5. Dominioni L, Rotolo N, Poli A, Paolucci M, Sessa F, D’Ambrosio V, et al. Self-selection effects in smokers attending lung cancer screening. A 9.5-year population-based cohort study in Varese, Italy. J Thorac Oncol. 2010;5:428-35.

6. Fontana RS, Sanderson DR, Woolner LB, Taylor WF, Miller WE, Muhm JR, et al. Screening for lung cancer: a critique of the Mayo Lung Project. Cancer. 1991;67(4 Suppl):1155-64.

7. National Cancer Institute. Available from: http://www.cancer. gov/cancertopics/pdq/screening/lung/HealthProfessional/page4. Accessed Aug. 1, 2010.

8. Fontana RS, Sanderson DR, Miller WE, Woolner LB, Taylor WF, Uhlenhopp MA. The Mayo Lung Project: preliminary report of "early cancer detection" phase. Cancer. 1972;30:1373-82.

9. Woolner LB, Fontana RS, Sanderson DR, Miller WE, Muhm JR, Taylor WF, et al. Mayo Lung Project. Evaluation of lung cancer screening through December 1979. Mayo Clin Proc. 1981;56:544-55.

10. Manser R, Irving LB, Stone C, Byrnes G, Abramson MJ, Campbell D. Screening for lung cancer. Cochrane Database Syst Rev. 2004; Issue 1. Art. No.: CD001991. doi:10.1002/14651858. CD001991.pub2.

11. Marcus PM, Bergstralh EJ, Zweig MH, Harris A, Offord KP, Fontana RS. Extended lung cancer incidence follow-up in the Mayo Lung Project and overdiagnosis. J Natl Cancer Inst. 2006;98:748-56.

12. Marcus PM, Bergstralh EJ, Fagerstrom RM, Williams DE, Fontana RS, Taylor WF, et al. Lung cancer mortality in the Mayo Lung Project: impact of extended follow-up. J Natl Cancer Inst. 2000;92:1308-16. 